and hearing, which enable her to keep herself from killing her young, and to protect them from other dangers. All of these features should then be noted.

Third, notes as to the character of the product should be taken. By this is meant its actual value as a carcass. Pigs vary largely in the per cent of carcass yielded, and in the quality of meat produced. The market value is affected by these features and a consideration of them should therefore enter into the determination of the value of the sow as an economical producer of meat.

Fourth, a record of the actual number of pounds produced by each sow through virtue of her litter should be kept. This really constitutes her yield, as did the wheat, that of the 16 square inches of earth utilized. This after all is the vital feature and where yield is present to high degree, all the other features, except good quality, must be.

Given in the data kept, the number of pounds of meat produced by each sow through her pigs, and the total feeds required by them to do it, then the number of pounds of feed required to produce one pound of gain can be determined. To the sow that has produced the greatest number of pounds of good quality meat on the smallest feed will go the laurels. She will have proved her right to be the founder of a new line -a line to be distinguished by its highly economic production of good meat.

It is believed by the writer that some such scheme as the one outlined must in a general way be followed by swine breeders before any very great improvement can be intelligently and surely made along the line of economic production. Such a scheme; while it must assume gigantic proportions, and cover a long period of years, if sure results are to be reached, still makes possible the discovery of the "occasional" animal of outstanding value and the preservation and reproduction of its blood line.

\title{
FUNDAMENTAL PRINCIPLES OF SUCCESSFUL SWINE BREEDING
}

By Wм. Dietruch, Illinois Experimental Station, Urbana, Ill.

All swine breeding cannot be called successful. Many 'so-called breeders are not breeders at all in the true sense of the word, but only multipliers of the species. The extent of their breeding operations is confined to the mating of sire and dam, making possible an increase in the number of individuals.

The breeder or the individual back of breeding operations is a greater factor in successful swine breeding than any other condition or any other 
set of conditions, possibly greater than all other conditions combined. So long as it is possible to render a hog useless for future breeding operations by mismanaged feeding during the course of a very short period, it can easily be seen that successful swine breeding depends very largely upon the ability, as a feeder of swine, of the individual back of such operations. It is not generally known today what constitutes good feeding or in other words what the factors are that must be taken into consideration. Where good results are obtained it is largely by accident or simply because the feeder happens by nature to be so constituted that he does the feeding in accordance with the laws of nature.

The ability of the breeder to select properly. is perhaps of greater importance than his ability as a feeder. To be a critical judge of swine the breeder must be able to see a hog by points, know the value of the different points, and know how these go together to the best possible advantage and not only be able to see the hog as an individual but also as one lump sum. Aside from this he must understand the principles of breeding and know what characters appear in swine and know the transmissibility of different characters and the law of chance according to which these characters combine and reappear in succeeding generations.

Swine can be reproduced very quickly. By taking advantage of natural variations the breeder can, on account of the readiness with which they are reproduced, mold the type very easily. The success or failure then of such breeding operations will practically be in the hands of the breeder. He can improve the breed or type or can allow it to retrograde according as his ability for this work will permit. To be successful in this work a man must not only have in mind the type that is most useful but he must also be able to judge of the future so as to know what future demands are likely to be. It is only the man who can produce most nearly what the market demands that can be considered to be most successful.

Aside from these various considerations the integrity of the breeder must be taken into consideration for no man can be called successful as a breeder if he "works the game" only for his own financial interest and irrespective of strict honesty, and not for the good of the breed. 